\title{
Tegafur/gimeracil/oteracil (S-I) approved for the treatment of advanced gastric cancer in adults when given in combination with cisplatin: a review comparing it with other fluoropyrimidine-based therapies
}

This article was published in the following Dove Press journal:

OncoTargets and Therapy

I4 November 201।

Number of times this article has been viewed

\section{Masao Kobayakawa \\ Yasushi Kojima}

Department of Gastroenterology, National Center for Global Health and Medicine, Tokyo, Japan
Correspondence: Masao Kobayakawa

I-2I-I Toyama, Shinjuku-ku,

Tokyo 162-8655, Japan

Tel +8I $332027|8|$

Fax +8I $33207 \quad 038$

Email mkobaya@hosp.ncgm.go.jp

\begin{abstract}
S-1 is a combination of three pharmacological compounds, namely tegafur, gimeracil, and oteracil potassium. Tegafur is a prodrug of 5-fluorouracil (5-FU), an oral fluoropyrimidine, and it has been developed as a replacement for infusional 5-FU therapy. S-1-based chemotherapy and the combination of S-1 and cisplatin are the most reasonable first-line standards for unresectable advanced gastric cancer in Japan. However, the application of S-1 for gastric cancer has been delayed in Western countries. One reason for this delay is that the pharmacokinetics of tegafur is affected by polymorphisms in cytochrome P-450 2A6, and consequently 5-FU concentrations in the plasma are more likely to be elevated in patients from Western countries. Although the dose of S-1 was reduced compared with the approved dose in Japan, a global Phase III study reported similar results regarding overall survival between S-1 plus cisplatin and infusional 5-FU plus cisplatin arms. Significant safety advantages were observed in the S-1 plus cisplatin arm compared with the infusional 5-FU plus cisplatin arm. S-1 plus cisplatin has become acceptable for Western countries, also, as a choice for unresectable advanced gastric cancer. Comparisons with capecitabine and combination of several targeting agents with S-1 are expected in the future.
\end{abstract}

Keywords: S-1, fluoropyrimidine, gastric cancer, chemotherapy

\section{Introduction}

Gastric cancer is the second most frequent cancer-related cause of death. It is more prevalent in East Asia and Central and South America than in other countries. The incidence of gastric cancer worldwide is estimated to be 934,000 cases, accounting for an estimated 700,000 to 800,000 deaths annually. Approximately half of new gastric cancer cases occur in East Asia, including 41\% in China and 11\% in Japan. ${ }^{1,2}$

For unresectable advanced or recurrent gastric cancer, systemic chemotherapy has become the standard treatment, with the goal of therapy being to provide palliation and prolong survival. Various randomized trials comparing 5-fluorouracil (5-FU) alone and the combination of 5-FU and other drugs have been performed to evaluate treatments. ${ }^{3-5}$ In the Japan Clinical Oncology Group 9205 trial, neither cisplatin (also known as CDDP) plus 5-FU (CF) nor uracil and tegafur plus mitomycin produced a significantly superior overall survival than 5-FU alone (median survival time $[\mathrm{MST}], 7.3,6.0$, and 7.1 months, respectively), although response rate (RR) and 
progression-free survival (PFS) in the CF arm were better than those of 5-FU alone (RR: 34\% vs 11\%, median PFS: 3.9 months vs 1.9 months). ${ }^{5}$ Consequently, 5-FU alone has been considered a reference arm for chemotherapy trials of unresectable gastric cancer in Japan. The CF regimen also did not prolong survival compared with survival obtained with 5-FU alone in a Korean study. ${ }^{4}$ However, CF has been considered the best reference arm in Western countries because RR and PFS in the CF arm were better than those of 5-FU alone. In Europe, triplet regimens have been utilized to improve survival. The superiority of the combination of epirubicin plus CF (ECF) over a combination of 5-FU plus doxorubicin plus high-dose methotrexate in terms of overall survival was demonstrated. ${ }^{6}$ MST of ECF was only 8.9 months, and no study was conducted to evaluate the effect of the addition of epirubicin to CF. Therefore, it is difficult to state that the addition of epirubicin to CF has been established for unresectable gastric cancer. The V325 trial compared docetaxel plus CF with CF alone, and indicated a significantly prolonged overall survival. ${ }^{7}$ However, docetaxel plus CF still has limited acceptance as a standard treatment for unresectable advanced gastric cancer because of the small benefit on overall survival of 0.6 months and its toxicity profile.

Recently, oral fluoropyrimidines have been developed as replacements for infusional 5-FU therapy and they have been indicated for various advanced cancers such as colonic, breast, and gastric cancers. In 2011, the Committee for Medicinal Products for Human Use, a division of the European Medicines Agency, issued an opinion recommending the approval of S-1 for treatment in adults with advanced gastric cancer when given in combination with CDDP. This review focuses on the history of S-1 development for chemotherapy for advanced gastric cancer, considering the ethnic differences between Western and Asian countries.

\section{Ethnic differences between Western countries and Japan}

There are many differences between Western countries and Japan regarding gastric cancer. In Japan, because of the high prevalence of gastric cancer, a nationwide mass screening system and endoscopy techniques have been developed. More than half of the gastric cancer cases in Japan are detected at an early stage, compared to $20 \%-30 \%$ cases in the United States.

The localization of gastric cancer, too, differs between Japan and Western countries. In Japan, the rate of Helicobacter pylori infection is very high, and more than
$90 \%$ of the cases of gastric cancers are localized in noncardiac regions; in addition, almost all are adenocarcinomas. Conversely, the incidence of gastric cancers localized in the cardiac region and the gastroesophageal junction has been rapidly rising in Western countries, especially in the United States. ${ }^{8}$ Adenocarcinomas arising in Barrett's esophagus can be classified either as gastroesophageal junction carcinoma or as esophageal carcinoma. Even squamous cell carcinoma in esophagus was eligible for inclusion in some clinical trials of gastric cancer in Western countries.

Several randomized trials were performed to evaluate treatments for metastatic gastric cancer worldwide. However, drug characteristics such as clearance by an enzyme with genetic polymorphisms and a steep dose-response curve will make differences in the safety and efficacy profiles more likely. Conversely, a lack of metabolism or active excretion, a wide therapeutic dose range, and a flat dose-response curve will reduce the possibility of ethnic differences. ${ }^{9}$ Many cytotoxic anticancer drugs are classified as belonging to the former type. Both docetaxel and tegafur, which are used to treat gastric cancer, are affected by enzyme activity. Docetaxel, for example, causes a high incidence of neutropenia in Asian patients because of lower cytochrome P-450 (CYP)3A5*3 activity compared with that in Caucasian patients. ${ }^{10}$

\section{Development of oral fluoropyrimidines}

Oral fluoropyrimidines have been developed as inactive prodrugs of 5-FU that are absorbed intact through the gastrointestinal mucosa and are converted to 5-FU by one or more enzyme systems. 5-FU exerts its antitumor effects through several mechanisms, including inhibition of ribonucleic acid synthesis and function, inhibition of thymidylate synthase activity, and incorporation into DNA, leading to DNA strand breaks. ${ }^{11,12}$ When 5 -FU is orally administered, extensive first-pass metabolism of 5-FU in the gastrointestinal wall and liver decreases 5-FU plasma levels and causes severe intestinal mucosal damage. ${ }^{13,14}$

The pharmacokinetics of oral fluoropyrimidines is similar to infusional 5-FU, but not bolus 5-FU. A meta-analysis comparing bolus infusion vs continuous infusion of 5-FU in patients with colorectal cancer revealed a small survival benefit (approximately 24 days) and significant toxicity for continuous infusion over bolus infusion. ${ }^{15}$ Specifically, continuous infusion was associated with far less myelosuppression than bolus administration ( $4 \%$ vs $31 \%$ ), but continuous infusion was associated with more hand-foot syndrome than bolus administration ( $34 \%$ vs $13 \%)$. 
The primary and rate-limiting enzyme involved in 5-FU metabolism is dihydropyrimidine dehydrogenase (DPD). To prevent inactivation by first-pass metabolism in the liver, oral fluoropyrimidines have been developed together with inhibitors of DPD. Genetic polymorphisms affect DPD activity, with $2 \%-4 \%$ of the population estimated to be deficient in the enzyme. ${ }^{16}$

S-1 (Taiho Pharmaceutical Company, Tokyo, Japan) is a combination of three pharmacological compounds (tegafur, gimeracil [CDHP], and oteracil potassium [Oxo]) in a 1:0.4:1 molar ratio. ${ }^{17}$ Figure 1 shows the metabolic pathway of S-1. Tegafur [R,S-1-1(tetrahydrofuran-2-yl)-5-FU] is a prodrug that is mainly converted by liver enzyme CYP2A6 to 5-FU. It is first hydroxylated to 5'-hydroxytegafur and eventually converted to 5 -FU. ${ }^{18} \mathrm{CYP} 2 \mathrm{~A} 6$ gene variants other than wild-type (CYP2A6*1) have been identified. The combined frequencies of the alleles lacking or exhibiting reduced enzymatic activity for nicotine metabolism $(* 2, * 4, * 5, * 7$, $* 9, * 10, * 11, * 17, * 19$, and $* 20$ ) were reported to be $9.1 \%$, $21.9 \%, 42.9 \%$, and $50.5 \%$ in Caucasian, African-American, Korean, and Japanese subjects, respectively. ${ }^{19}$ Japanese individuals also have lower expression of the CYP2A6 isozyme than Caucasian individuals. ${ }^{20}$ In patients with two variant alleles of CYP2A6 $(* 4, * 7$, and *9), the clearance of tegafur was $58 \%$ lower than that in patients with the wild-type or *1 variant allele. ${ }^{21}$ It is postulated that the higher efficacy of CYP2A6 is one of the causes of the more rapid conversion of tegafur to 5-FU in Caucasian subjects, who achieve a higher area under the curve of 5-FU than Asians. CDHP is an inhibitor of DPD, which degrades 5-FU to inactive 5-fluorodihydrouracil in the liver and prolongs the half-life of
5-FU. CDHP is primarily cleared by the kidneys. In patients with renal insufficiency, CDHP renal clearance is decreased, and 5-FU exposure is, thus, increased. ${ }^{21}$ Renal function, as reflected by creatinine clearance, was the primary factor that influenced CDHP exposure and 5-FU exposure. Oxo inhibits the phosphorylation of 5-FU to fluorouridine monophosphate, an active intermediary metabolite of 5-FU, by orotate phosphoribosyltransferase in the gastrointestinal tract, thereby reducing the toxic effects of 5-FU to the gastrointestinal tract. However, the protective value of Oxo against 5-FU-induced diarrhea in humans is not well established, because 5-FU can also be phosphorylated by uridine phosphorylase or thymidine phosphorylase, generating 5-fluorodeoxyuridine monophosphate, and thus, resulting in diarrhea. By those mechanisms, this drug is designed to enhance the efficacy of tegafur and reduce the toxicity of tegafur in the gastrointestinal tract. Although CYP2A6 variants are associated with the pharmacokinetic variability of tegafur, CDHP is a key determinant in the pharmacokinetic variability of 5-FU. ${ }^{21}$ The tolerance to fluoropyrimidines themselves is believed to be different among United States, Europe, and East Asia, and it is speculated that high folic acid levels in the diet may be responsible for the weak tolerance in Western populations. ${ }^{22}$ The incidence of adverse reactions is also affected by the protective effect of Oxo. Consequently, adjustment of S-1 by screening of CYP2A6 polymorphisms has not been established.

Capecitabine (N4-pentyloxycarbonyl-5'-deoxy5 -fluorocytidine) is another oral fluoropyrimidine. Figure 2 shows the metabolic pathway of capecitabine. It is a prodrug of a 5-FU prodrug (doxifluridine) and is



Figure I Metabolism of S-I.

Abbreviations: 5-FU, 5-fluorouracil; CDHP, gimeracil; CYP2A6, cytochrome P450 2A6; DPD, dihydropyrimidine dehydrogenase; FUH2, 5-fluorodihydrouracil; FUMP, fluorouridine monophosphate; OPRT, orotate phosphoribosyltransferase; Oxo, oteracil potassium. 


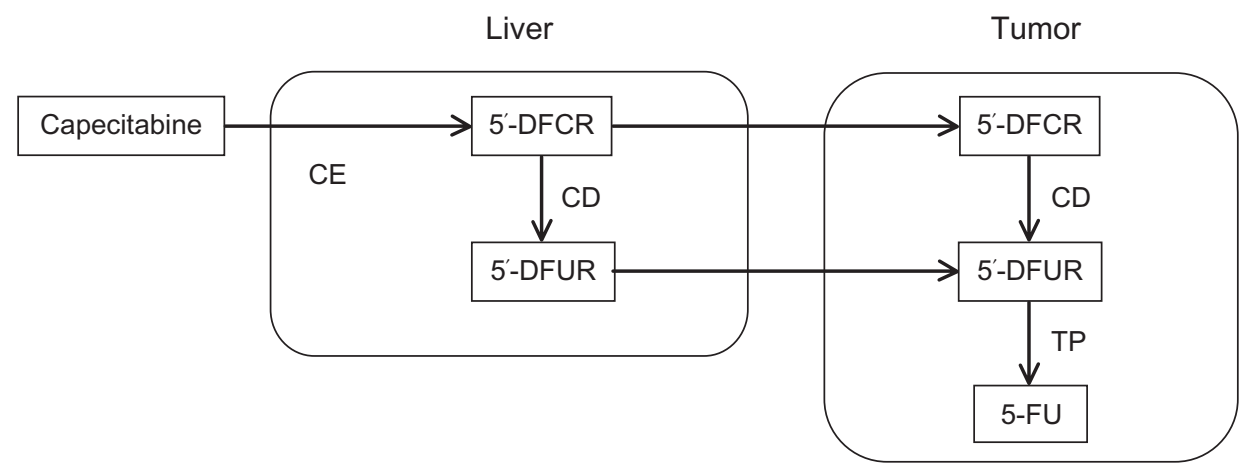

Figure 2 Metabolism of capecitabine.

Abbreviations: CE, carboxylesterase; 5'-DFCR, 5'-deoxyfluorocytidine, 5'-DFUR, doxifluridine; 5-FU, 5-fluorouracil; CD, cytidine deaminase; TP, thymidine phosphorylase.

designed to minimize the substantial local gastrointestinal toxicity of doxifluridine without decreasing its antitumor efficacy. Capecitabine itself is inactive. It is reliably absorbed unchanged from the gastrointestinal tract, and then converted through three enzymatic reactions to 5-FU. It is first converted to $5^{\prime}$-deoxyfluorocytidine in the liver by carboxylesterase, and then converted to doxifluridine by cytidine deaminase, a ubiquitous enzyme found in the liver, plasma, and tumor tissue. The toxic intermediary compound doxifluridine is then converted to 5-FU by thymidine phosphorylase, an enzyme that may be more abundant in tumors than in normal tissue, thus potentially resulting in tumor 5-FU concentrations that far exceed its plasma levels and greater antineoplastic effects with lower toxicity. The differences in the metabolic systems of these drugs affect the optimal doses and safety profiles among patients in different regions, although both S-1 and capecitabine are oral prodrugs of 5-FU.

\section{S-I-based chemotherapy for unresectable advanced gastric cancer in Asia}

S-1 has been developed mainly in Japan because the pharmaceutical company producing S-1 is a domestic Japanese company and there are sufficient numbers of patients with gastric cancer in Japan for clinical trials. Phase II trials of S-1 monotherapy $\left(40 \mathrm{mg} / \mathrm{m}^{2}\right.$, twice a day, on days $1-28$, every 6 weeks) were conducted in Japan, and they reported an RR of $44 \%-54 \%$ in patients with advanced gastric cancer. ${ }^{23-25} \mathrm{In}$ 1999 , the Japanese government approved this drug for treating gastric cancer on the basis of the results of two domestic Phase II trials. Before the results of a Phase III trial were available, the use of S-1 rapidly increased in clinical practice in Japan because of its high RR and its convenience of oral therapy as a substitute for infusional 5-FU therapy.
After S-1 was approved by the government, a Phase III trial comparing $5-\mathrm{FU}$ alone $\left(800 \mathrm{mg} / \mathrm{m}^{2}\right.$ on days $1-5$ every 4 weeks), irinotecan plus CDDP (irinotecan: $70 \mathrm{mg} / \mathrm{m}^{2}$ on days 1 and 15; CDDP: $80 \mathrm{mg} / \mathrm{m}^{2}$ on day 1, every 4 weeks), and S-1 alone (40 mg/m², twice a day, on days 1-28, every 6 weeks) was conducted in Japan (Japan Clinical Oncology Group 9912). Both irinotecan plus CDDP and S-1 alone produced a significantly higher RR and longer PFS than the control arm of 5-FU alone (RR: $38 \%$ vs $28 \%$ vs $9 \%$, median PFS: 4.8 months vs 4.2 months vs 2.9 months). In terms of overall survival, this study demonstrated that S-1 was not inferior to 5-FU monotherapy (MST: 11.4 months vs 10.8 months, hazard ratio: 0.83 ). However, there was no demonstration of the significant superiority of irinotecan plus CDDP over 5-FU (MST: 12.3 months vs 10.8 months; hazard ratio: 0.85$).{ }^{26}$ This Phase III trial established oral S-1 as a substitute for standard infusional 5-FU therapy for unresectable gastric cancer in Japan.

Regarding S-1 combination therapy, a Phase I/II study of S-1 combined with CDDP (S-1: $40 \mathrm{mg} / \mathrm{m}^{2}$, twice a day, on days 1-21; CDDP: $60 \mathrm{mg} / \mathrm{m}^{2}$ on day 8 , every 5 weeks) in patients with advanced gastric cancer was conducted, and it reported an RR of 76\%, a median overall survival of 383 days, and tolerable toxicity. ${ }^{27}$ In the Randomized Phase III Study of S-1 Alone Versus S-1 Plus CDDP in Advanced Gastric Cancer (SPIRITS) trial, which compared S-1 monotherapy $\left(40 \mathrm{mg} / \mathrm{m}^{2}\right.$, twice a day, on days $1-28$, every 6 weeks) with a combination of S-1 and CDDP (S-1: $40 \mathrm{mg} / \mathrm{m}^{2}$, twice a day, on days 1-21; CDDP: $60 \mathrm{mg} / \mathrm{m}^{2}$ on day 8 , every 5 weeks), the combination arm yielded a significantly higher RR and longer PFS and overall survival than the control arm (RR: $54 \%$ vs $31 \%$, median PFS: 6.0 months vs 4.0 months, MST: 13.0 months vs 11.0 months). ${ }^{28}$ Since the SPIRITS trial, the combination of S-1 and CDDP has been considered the standard first-line chemotherapy for unresectable advanced gastric cancer in Japan. 
A Phase III trial comparing S-1 plus irinotecan (S-1: $40 \mathrm{mg} / \mathrm{m}^{2}$, twice a day, on days $1-21$; irinotecan: $80 \mathrm{mg} / \mathrm{m}^{2}$ on days 1 and 15 , every 5 weeks) with S-1 alone $\left(40 \mathrm{mg} / \mathrm{m}^{2}\right.$, twice a day, on days 1-28, every 6 weeks) was also conducted in Japan. ${ }^{29}$ Although S-1 plus irinotecan achieved a longer median survival than S-1 monotherapy (MST: 12.5 months vs 10.5 months) and was well tolerated, it did not produce significantly superior overall survival.

Recently the results of a Phase III trial comparing S-1 plus docetaxel (S-1: $40 \mathrm{mg} / \mathrm{m}^{2}$, twice a day, on days 1-14; docetaxel: $40 \mathrm{mg} / \mathrm{m}^{2}$ on day 1 , every 3 weeks) with S-1 alone (40 mg/ $/ \mathrm{m}^{2}$, twice a day, on days $1-28$, every 6 weeks) conducted in Japan and Korea was reported in abstract form..$^{30}$ The combination of S-1 plus docetaxel did not meet the primary endpoint of overall survival ( $\log$-rank $P=0.1416$, hazard ratio: 0.88). Regarding the combination of S-1 with other cytotoxic drugs, CDDP only but not irinotecan and docetaxel, provided a significant additional benefit on overall survival.

In Japan and Korea, a randomized trial of 3-weekly vs 5-weekly schedule of S-1 plus CDDP for advance gastric cancer is ongoing. ${ }^{31}$ The primary endpoint is PFS, and this study is designed to test the superiority (or noninferiority) of the 3-week regimen over the 5-week standard regimen.

\section{S-I-based chemotherapy for gastric cancer in Western countries}

Regarding the application of S-1-based chemotherapy in countries other than Japan, a Phase I trial was conducted in Caucasian patients in the United States to establish the maximum tolerated dose of S-1 plus CDDP. ${ }^{32}$ Patients received CDDP intravenously on day 1 and S-1 orally twice a day on days 1-21 every 4 weeks. At level 1, the S-1 dose was $25 \mathrm{mg} / \mathrm{m}^{2}$ twice a day, but it was increased by $5 \mathrm{mg} / \mathrm{m}^{2}$ per dose for the next level. CDDP was administered at $75 \mathrm{mg} / \mathrm{m}^{2}$ (for levels 1 and 2), but was then reduced to $60 \mathrm{mg} / \mathrm{m}^{2}$ (level 1A). Dose-limiting toxicities occurred at levels $1 \mathrm{~A}$ and 2, and the most common dose-limiting toxicities observed at the maximum tolerated dose were fatigue, diarrhea, and diarrhea-associated dehydration. In this study, the area under the curve of 5-FU was significantly correlated with severe diarrhea. There was also a significant correlation between the area under the curve of cyanuric acid, an inactive metabolite of Oxo, and severe diarrhea. Although Oxo might be metabolized so rapidly to cyanuric acid that more Oxo might be necessary to prevent diarrhea in Western patients, the optimal dose of S-1 and CDDP in combination (S-1: $25 \mathrm{mg} / \mathrm{m}^{2}$ twice a day, on days 1-21; CDDP: $75 \mathrm{mg} / \mathrm{m}^{2}$ on day 1) for Western patients has been defined (Table 1).
Table I The optimal dose of S-I-based chemotherapy

\begin{tabular}{llll}
\hline Regimens & Drugs & Dose & Cycle \\
\hline S-I alone & S-I & $\begin{array}{l}40 \mathrm{mg} / \mathrm{m}^{2} \text {, twice a day, } \\
\text { on days I-28 }\end{array}$ & 6 weeks \\
S-I + CDDP & S-I & $\begin{array}{l}40 \mathrm{mg} / \mathrm{m}^{2} \text {, twice a day, } \\
\text { on days I-28 }\end{array}$ & 5 weeks \\
(Japanese dose) & CDDP & $60 \mathrm{mg} / \mathrm{m}^{2}$ on day 8 & \\
S-I + CDDP & S-I & $25 \mathrm{mg} / \mathrm{m}^{2}$, twice a day, & 4 weeks \\
(Western dose) & & on days I-28 & \\
& CDDP & $75 \mathrm{mg} / \mathrm{m}^{2}$ on day I & \\
\hline
\end{tabular}

Abbreviation: $C D D P$, cisplatin.

Using the Western dose of S-1 plus CDDP on the basis of the results of the Phase I trial, the combination was studied in a multicenter Phase II trial of untreated, advanced gastric or gastroesophageal adenocarcinoma patients in North American and European institutions. ${ }^{33,34}$ The majority of patients (75\%) were Caucasian and $15 \%$ were African-American and/or Latino. This study demonstrated that RR was $51 \%$ and MST was 10.9 months, and the combination of a reduced dose of S-1 plus CDDP exhibited a favorable toxicity profile.

The First-line Advanced Gastric Cancer Study (FLAGS) trial comparing an experimental regimen of S-1 plus CDDP (S-1: $25 \mathrm{mg} / \mathrm{m}^{2}$ twice a day, on days 1-21; CDDP: $75 \mathrm{mg} / \mathrm{m}^{2}$ on day one, every 4 weeks) with a reference regimen of CF (5-FU: $1000 \mathrm{mg} / \mathrm{m}^{2}$ continuous infusion on days $1-5$; CDDP: $100 \mathrm{mg} / \mathrm{m}^{2}$ on day 1 , every 4 weeks) was conducted in 24 countries and 146 centers in the United States, Eastern and Western Europe, South America, Australia, and former Soviet Union nations. ${ }^{35}$ Eighty-six percent of the patients were Caucasian. African-American, Asian, American Indian, and Alaska Native patients each comprised less than 1.2\% of the study population. The study was designed to confirm the superiority of overall survival in S-1 plus CDDP over CF (estimated MST was 10.5 months vs 8.5 months). MST was 8.6 months in the S-1 plus CDDP arm and 7.9 months in the $\mathrm{CF}$ arm (hazard ratio: $0.92,95 \%$ confidence interval [CI]: $0.80-1.05, P=0.20$ ). RR was $29.1 \%$ for the S- 1 plus CDDP arm and $31.9 \%$ for the CF arm. Median PFS was 4.8 months (95\% CI: 4.0-5.5 months) in the S-1 plus CDDP arm and 5.5 months in the CF arm (95\% CI: 4.4-5.8 months). Primary endpoint was not achieved, and S-1 plus CDDP did not prolong overall survival compared with the findings for $\mathrm{CF}$, although the overall survival was similar in both arms. Hematologic adverse events and treatment-related deaths were less common in the S-1 plus CDDP arm than in the $\mathrm{CF}$ arm, with neutropenia, thrombocytopenia, and leucopenia being significantly more frequent (Table 2). Median overall survival in the S-1 plus CDDP arm in the FLAGS 
Table 2 Adverse events of First-line Advanced Gastric Cancer Study trial

\begin{tabular}{|c|c|c|c|c|}
\hline \multirow[t]{2}{*}{ Toxicity } & \multicolumn{2}{|c|}{$\begin{array}{l}\text { S-I + CDDP } \\
(n=52 I)\end{array}$} & \multicolumn{2}{|c|}{$\begin{array}{l}\text { 5-FU + CDDP } \\
(n=508)\end{array}$} \\
\hline & $\begin{array}{l}\text { All } \\
\text { (\%) }\end{array}$ & $\begin{array}{l}\text { Grades 3-4 } \\
\text { (\%) }\end{array}$ & $\begin{array}{l}\text { All } \\
(\%)\end{array}$ & $\begin{array}{l}\text { Grades 3-4 } \\
\text { (\%) }\end{array}$ \\
\hline Anemia & 81.6 & 20.7 & 78.1 & 20.9 \\
\hline Neutropenia & $60.5^{*}$ & 32.3 & $82.5^{*}$ & 63.6 \\
\hline Thrombocytopenia & $36.8^{*}$ & 8.3 & $50.5^{*}$ & 13.5 \\
\hline Leucopenia & $54.9 *$ & 13.7 & 76.1 & 33.2 \\
\hline Febrile neutropenia & $5.0^{*}$ & & $14.4^{*}$ & \\
\hline Vomiting & $48.0^{* *}$ & 7.9 & $55.3 * *$ & 9.6 \\
\hline Diarrhea & $29.2^{*}$ & 4.8 & $38.4 *$ & 4.5 \\
\hline Hypokalemia & $6.9 *$ & $3.6^{*}$ & $16.7^{*}$ & $10.8^{*}$ \\
\hline Stomatitis & $6.3^{*}$ & $1.3^{*}$ & $30.3^{*}$ & $13.6 *$ \\
\hline Mucosal inflammation & $3.8^{*}$ & $0.8^{*}$ & $29.9 *$ & $8.1^{*}$ \\
\hline Calculated & $22.6 * *$ & & $40.9 * *$ & \\
\hline \multicolumn{5}{|l|}{$\mathrm{CrCL}<50 \mathrm{~mL} /$ minute } \\
\hline All toxic deaths & $2.5^{* *}$ & & $4.9 * *$ & \\
\hline
\end{tabular}

Notes: $* P<0.01$; $* * P<0.05$.

Abbreviations: 5-FU, 5-fluorouracil; CDDP, cisplatin; $\mathrm{CrCL}$, creatinine clearance.

trial was shorter than that in the SPIRITS trial (8.6 months vs 13.0 months), although PFS was similar (4.8 months vs 6.0 months) (Table 3). The reason may be associated with patient characteristics and medical infrastructure. In the SPIRITS trial, $65 \%$ of patients had target lesions and $74 \%$ of patients received second-line therapy. In the FLAGS trial, $96 \%$ of patients had target lesions and only $31 \%$ received second-line therapy.

A Phase III study evaluating the superiority of S-1 plus CDDP over CF is now in progress for diffuse gastric and esophagogastric junction cancers in the United States and European countries based on subgroup analysis of the FLAGS trial, which revealed better effect in patients with diffuse-type carcinoma.

\section{S-I for adjuvant chemotherapy}

In the Adjuvant Chemotherapy Trial of S-1 for Gastric Cancer study, the S-1 arm had a higher proportion of overall survival than the surgery-only arm in Japan. ${ }^{36}$ Patients with stage II or III gastric cancer who underwent curable gastrectomy with extended (D2) lymph-node dissection were included. S-1 was administered at $40 \mathrm{mg} / \mathrm{m}^{2}$ twice a day for 4 weeks every 6 weeks and continued for 1 year. However, it is not easy to apply this result to other countries. Regarding gastrectomy, D2 dissection is the standard surgical technique used in Japan, whereas D1 dissection is used in Western countries. Two European randomized trials that compared D1 and D2 gastrectomy failed to demonstrate any survival benefit of D2 over D1. ${ }^{37,38}$ This failure was attributed to the $10 \%$ higher mortality rate in the $\mathrm{D} 2 \mathrm{arm}$. A large randomized trial comparing D2 dissection with D2 plus paraaortic nodal dissection (Japan Clinical Oncology Group 9501) revealed no significant survival benefit of D2 plus paraaortic nodal dissection over D2, but the 5-year survival and hospital mortality rates were approximately $70 \%$ and $0.8 \%$, respectively. ${ }^{39}$ These differences in prognosis after surgery could affect the evaluation of adjuvant chemotherapy for gastric cancer.

\section{Development of capecitabine-based chemotherapy}

A randomized noninferiority trial comparing capecitabine plus CDDP (XP) (1000 mg/m² twice a day on days 1-14; CDDP: $80 \mathrm{mg} / \mathrm{m}^{2}$ on day 1 ) with CF (5-FU: $800 \mathrm{mg} / \mathrm{m}^{2}$ per day on days 1-5; CDDP: $80 \mathrm{mg} / \mathrm{m}^{2}$ on day 1) demonstrated that XP was not inferior to CF in terms of PFS. Median PFS and median overall survival were 5.6 months and 10.5 months in the XP arm and 5.0 months and 9.3 months in the CF arm, respectively. ${ }^{40}$

Table 3 Results of Phase III trials of S-I-based chemotherapy

\begin{tabular}{lllllll}
\hline Study (region) & Regiment & $\begin{array}{l}\text { Number } \\
\text { of patients }\end{array}$ & RR (\%) & PFS (months) & MST (months) & P value \\
\hline JCOG99I2 & 5-FU & 234 & 9 & 2.9 & 10.8 & NS \\
(Japan) & CDDP + & 236 & 38 & 4.8 & 12.3 & Noninferiority \\
& irinotecan + S-I & 234 & 28 & 4.2 & 11.4 & P 0.05 \\
SPIRITS & S-I & 150 & 3 & 4.0 & 11.3 & NS \\
Japan) & S-I + CDDP & 148 & 54 & 6.0 & 13.0 & NS \\
GC030I/TOP-002 & S-I & 160 & 26.9 & 3.6 & 10.5 & \\
Japan) & S-I + irinotecan & 155 & 41.5 & 4.5 & 12.8 & NS \\
START & S-I & 313 & 18.4 & 4.0 & 13.7 & \\
Japan and Korea) & S-I + docetaxel & 310 & 30.3 & 4.7 & 8.6 & \\
FLAGS & S-I + CDDP & 521 & 29.1 & 4.8 & 7.9 & \\
(Western) & 5-FU + CDDP & 508 & 31.9 & 5.5 & & \\
\hline
\end{tabular}

Abbreviations: 5-FU, 5-fluorouracil; CDDP, cisplatin; FLAGS, First-line Advanced Gastric Cancer Study; JCOG, Japan Clinical Oncology Group; MST, median survival time; NS, not significant; PFS, progression-free survival; RR, response rate; SPIRITS, Randomized Phase III Study of TS-I Alone Versus TS-I Plus CDDP in Advanced Gastric Cancer; START, Randomized Phase III Study of S-I Alone Versus S-I Plus Docetaxel in the Treatment for Advanced Gastric Cancer. 
Similar results were observed in a randomized multicenter Phase III study comparing capecitabine with FU and oxaliplatin with CDDP in patients with advanced esophagogastric cancer. ${ }^{41}$ Patients received either triplet therapy with ECF or epirubicin plus XP or triplet therapy with epirubicin plus oxaliplatin plus FU (EOF) or epirubicin plus oxaliplatin plus capecitabine (EOX). All four regimens were administered every 3 weeks (epirubicin: $50 \mathrm{mg} / \mathrm{m}^{2}$ on day 1; CDDP: $60 \mathrm{mg} / \mathrm{m}^{2}$ on day 1; oxaliplatin: $130 \mathrm{mg} / \mathrm{m}^{2}$ on day 1; capecitabine: $625 \mathrm{mg} / \mathrm{m}^{2}$ twice a day on days $1-21$; 5-FU: $200 \mathrm{mg} / \mathrm{m}^{2}$ on days $1-21$ ). Median survival times in the ECF, epirubicin plus XP, EOF, and EOX arms were 9.9, 9.9, 9.3, and 11.2 months, respectively. Noninferiority of the capecitabine group (epirubicin plus XP and EOX) to the FU group (ECF and EOF) and that of the oxaliplatin group (EOF and EOX) to the CDDP group (ECF and EOF) were confirmed. The toxic effects of capecitabine and FU were similar. These studies indicate that capecitabine can replace infusional 5-FU and that oxaliplatin can replace CDDP for patients with advanced gastric cancer.

\section{Comparison of S-I with capecitabine}

A small Phase II study comparing S-1 $\left(40 \mathrm{mg} / \mathrm{m}^{2}\right.$ twice a day for 4 weeks every 6 weeks) and capecitabine $\left(1250 \mathrm{mg} / \mathrm{m}^{2}\right.$ twice a day for 2 weeks every 3 weeks) in elderly patients with advanced gastric cancer in Korea revealed similar RR (28.9\% vs $27.2 \%$ ), time to progression (4.2 months vs 4.7 months), and overall survival (8.1 months vs 9.5 months) between the two arms. ${ }^{42}$ The incidence of grade 3-4 granulocytopenia was $4.8 \%$ with S-1 and $6.8 \%$ with capecitabine. Grade 3-4 nonhematologic toxicities included asthenia (7.1\% with S-1 vs $9.1 \%$ with capecitabine), anorexia ( $9.5 \%$ vs $6.8 \%)$, diarrhea ( $0 \%$ vs $2.3 \%$ ), and hand-foot syndrome ( $0 \%$ vs $6.8 \%$ ).

Hand-foot syndrome appeared to occur more often in the capecitabine arm than in the S-1 arm for Asian patients with gastric cancer. However, studies comparing S-1 at a reduced dose and capecitabine have never been conducted in Western countries, and further studies are necessary to compare the efficacy and safety between these two drugs as replacements for infusional 5-FU therapy.

\section{Combination with targeting agents}

Recently, several Phase III trials with monoclonal antibodies for gastric cancer have been conducted around the world. A randomized trial comparing capecitabine or $\mathrm{CF}$ alone with capecitabine or CF plus bevacizumab as a first-line therapy failed to demonstrate the superiority of overall survival. ${ }^{43}$
The overall survival of the reference arm was 12.1 months in Asia, 8.6 months in Europe, and 6.8 months in the United States. This may indicate that many important factors that affect survival, and thus, global studies combining populations from East Asia and other counties are not suitable for evaluating chemotherapy in gastric cancer patients.

A global randomized trial comparing 5-FU or capecitabine plus CF or XP plus trastuzumab based on the examination of human epidermal growth factor receptor-2 overexpression in gastric cancer tissues revealed a significantly superior overall survival of the trastuzumab combination arm (MST: 13.8 months vs 11.1 months) ${ }^{44}$ Cytotoxic drugs were repeated every 3 weeks (capecitabine: $1000 \mathrm{mg} / \mathrm{m}^{2}$ on days $1-14$ or 5-FU: $800 \mathrm{mg} / \mathrm{m}^{2}$ on day $1-5$; CDDP: $80 \mathrm{mg} / \mathrm{m}^{2}$ on day 1$)$. Trastuzumab was repeated every 3 weeks $(8 \mathrm{mg} / \mathrm{kg}$ initially followed by $6 \mathrm{mg} / \mathrm{kg}$ ). This trial included 101 Japanese patients among 594 total patients, and all Japanese patients received the XP regimen with or without trastuzumab. Mainly on the basis of this study, the Japanese government approved capecitabine and trastuzumab in 2011. Both S-1 and capecitabine are available for advanced gastric cancer, and direct comparisons of S-1-based chemotherapy and capecitabinebased chemotherapy are also expected in Japan.

The cetuximab in Combination with capecitabine and Cisplatin in Advanced Esophagogastric Cancer trial, which includes Japanese patients, is expected to define the role of cetuximab in combination with capecitabine and CDDP in the first-line setting for patients with advanced gastric or gastroesophageal junction adenocarcinoma. In Japan, a Phase II trial of cetuximab combination with S-1 plus CDDP is also ongoing. A randomized trial of EOX with or without panitumumab for advanced and locally advanced esophagogastric cancer is currently ongoing in Europe. ${ }^{45}$

In East Asia, several Phase I/II studies of the combination of S-1 plus CDDP with targeting agents are being conducted. Sorafenib combined with S-1 plus CDDP was investigated in a Japan-Korea Phase I/II study, but high incidence of hand-foot syndrome was reported. Sunitinib is now being evaluated in combination with S-1 plus CDDP or $\mathrm{XP}$ in Japan. Aflibercept, a fusion protein that functions as an inhibitor of vascular endothelial growth factor, is under development worldwide, and two Phase I studies, one in combination with S-1 and another with docetaxel, are currently underway in Japan.

\section{Conclusion}

S-1 at a reduced dose can be an apt replacement for infusional 5-FU therapy, even in Western countries. Moreover, safety 
profiles were better in the $\mathrm{S}-1$ plus CDDP arm than in the $\mathrm{CF}$ arm. Many regimens such as S-1 plus CDDP, XP, ECF, ECX, EOF, EOX, and docetaxel plus CF are available in Europe for patients with advanced gastric cancer. Additional effects of epirubicin or docetaxel on the combination of fluoropyrimidine and platinum analog have not been established. Only trastuzumab has improved the efficacy of the combination of fluoropyrimidines and platinum analogs in patients with human epidermal growth factor receptor-2-positive advanced gastric cancer. Regimens should be chosen after considering the safety profile of the regimen, patient condition, and ease of administration. Further studies of S-1-based chemotherapy for gastric cancer will be expected both in Japan and Western countries to determine the optimal first-line regimen for advanced gastric cancer.

\section{Disclosure}

The authors report no conflicts of interest in this work.

\section{References}

1. Parkin DM, Bray F, Ferlay J, Pisani P. Global cancer statistics, 2002. CA Cancer J Clin. 2005;55(2):74-108.

2. Garcia M, Jemal A, Ward EM, Hao Y, Siegel RL, Thun MJ. Global Cancer Facts and Figures 2007. Atlanta, GA: American Cancer Society; 2007.

3. Cullinan SA, Moertel CG, Wieand HS, et al. Controlled evaluation of three drug combination regimens versus fluorouracil alone for the therapy of advanced gastric cancer. J Clin Oncol. 1994;12(2):412-416.

4. Kim NK, Park YS, Heo DS, et al. A phase III randomized study of 5-fluorouracil and cisplatin versus 5-fluorouracil, doxorubicin, and mitomycin $\mathrm{C}$ versus 5-fluorouracil alone in the treatment of advanced gastric cancer. Cancer. 1993;71(12):3813-3818.

5. Ohtsu A, Shimada Y, Shirao K, et al. Randomized phase III trial of fluorouracil alone versus fluorouracil plus cisplatin versus uracil and tegafur plus mitomycin in patients with unresectable, advanced gastric cancer: The Japan Clinical Oncology Group Study (JCOG9205). J Clin Oncol. 2003;21(1):54-59.

6. Webb A, Cunningham D, Scarffe JH, et al. Randomized trial comparing epirubicin, cisplatin, and fluorouracil versus fluorouracil, doxorubicin, and methotrexate in advanced esophagogastric cancer. J Clin Oncol. 1997;15(1):261-267.

7. Van Cutsem E, Moiseyenko VM, Tjulandin S, et al. Phase III study of docetaxel and cisplatin plus fluorouracil compared with cisplatin and fluorouracil as first-line therapy for advanced gastric cancer: a report of the V325 study group. J Clin Oncol. 2006;24(31):4991-4997.

8. Blot WJ, Devesa SS, Kneller RW, Fraumeni JF Jr. Rising incidence of adenocarcinoma of the esophagus and gastric cardia. JAMA. 1991;265(10):1287-1289.

9. ICH Expert Working Group. Ethnic factors in the acceptability of foreign clinical data E5(R1). February 5, 1998. Available from: http:// www.ich.org/fileadmin/Public_Web_Site/ICH_Products/Guidelines/ Efficacy/E5_R1/Step4/E5_R1_Guideline.pdf. Accessed October 7, 2011.

10. Baker SD, Sparreboom A, Verweij J. Clinical pharmacokinetics of docetaxel: recent developments. Clin Pharmacokinet. 2006;45(3): $235-252$.

11. Heidelberger C, Chaudhuri NK, Danneberg P, et al. Fluorinated pyrimidines, a new class of tumour inhibitory compounds. Nature. 1957;179(4561):663-666.
12. Grem JL. 5-Fluoropyrimidines. In: Chabner BA, Longo DL, editors. Cancer Chemotherapy and Biotherapy. 2nd ed. Philadelphia, PA: Lippincott-Raven Publishers; 1996:149-211.

13. Fraile RJ, Baker LH, Buroker TR, Horwitz J, Vaitkevicius VK. Pharmacokinetics of 5-fluorouracil administered orally, by rapid intravenous and by slow infusion. Cancer Res. 1980;40(7):2223-2228.

14. Bajetta E, Colleoni M, Di Bartolomeo M, et al. Doxifluridine and leucovorin: an oral treatment combination in advanced colorectal cancer. J Clin Oncol. 1995;13(10):2613-2619.

15. Meta-Analysis Group in Cancer. Efficacy of intravenous continuous infusion of fluorouracil compared with bolus administration in advanced colorectal cancer. J Clin Oncol. 1998;16(1):301-308.

16. Meinsma R, Fernandez-Salguero P, Van Kuilenburg AB, Van Gennip AH, Gonzalez FJ. Human polymorphism in drug metabolism: mutation in the dihydropyrimidine dehydrogenase gene results in exon skipping and thymine uracilurea. DNA Cell Biol. 1995;14(1):1-6.

17. Shirasaka T, Shimamoto Y, Ohshimo H, et al. Development of a novel form of an oral 5-fluorouracil derivative (S-1) directed to the potentiation of the tumor selective cytotoxicity of 5-fluorouracil by two biochemical modulators. Anticancer Drugs. 1996;7(5): 548-557.

18. El-Sayed YM, Sadee W. Metabolic activation of ftorafur [R,S-1(tetrahyro-2-furanyl)-5-fluorouracil]: the microsomal oxidative pathway. Biochem Pharmacol. 1982;31(18):3006-3008.

19. Nakajima M, Fukami T, Yamanaka H, et al. Comprehensive evaluation of variability in nicotine metabolism and CYP2A6 polymorphic alleles in four ethnic populations. Clin Pharmacol Ther. 2006;80(3): 282-297.

20. Shimada T, Yamazaki H, Guengerich FP. Ethnic-related differences in coumarin 7-hydroxylation activities catalyzed by cytochrome P450 $2 \mathrm{~A} 6$ in liver microsomes of Japanese and Caucasian populations. Xenobiotica. 1996;26(4):395-403.

21. Hirose T, Fujita K, Nishimura K, et al. Pharmacokinetics of S-1 and CYP2A6 genotype in Japanese patients with advanced cancer. Oncol Rep. 2010;24(2):529-536.

22. Haller DG, Cassidy J, Clarke SJ, et al. Potential regional differences for the tolerability profiles of fluoropyrimidines. J Clin Oncol. 2008;26(13):2118-2123.

23. Sugimachi K, Maehara Y, Horikoshi N, et al. An early phase II study of oral S-1, a newly developed 5-fluorouracil derivative for advanced and recurrent gastrointestinal cancers. Oncology. 1999;57(3): 202-210.

24. Sakata Y, Ohtsu A, Horikoshi N, Sugimachi K, Mitachi Y, Taguchi T. Late phase II study of novel oral fluoropyrimidine anticancer drug S-1 (1 $\mathrm{M}$ tegafur- $0.4 \mathrm{M}$ gimestat- $1 \mathrm{M}$ otastat potassium) in advanced gastric cancer patients. Eur J Cancer. 1998;34(11):1715-1720.

25. Koizumi W, Kurihara M, Nakano S, Hasegawa K. Phase II study of S-1, a novel oral derivative of 5-fluorouracil, in advanced gastric cancer. Oncology. 2000;58(3):191-197.

26. Boku N, Yamamoto S, Shirao K, et al. Randomized phase III study of 5 -fluorouracil (5-FU) alone versus combination of irinotecan and cisplatin (CP) versus S-1 alone in advanced gastric cancer. (JCOG9912) [abstract]. J Clin Oncol. 2007;25 Suppl 18:LBA4513.

27. Koizumi W, Tanabe S, Saigenji K, et al. Phase I/II study of S-1 combined with cisplatin in patients with advanced gastric cancer. $\mathrm{Br} J$ Cancer. 2003;89(12):2207-2212.

28. Koizumi W, Narahara H, Hara T, et al. S-1 plus cisplatin versus S-1 alone for first-line treatment of advanced gastric cancer (SPIRITS trial): a phase III trial. Lancet Oncol. 2008;9(3):215-221.

29. Nakahara H, Iishi H, Imamura H, et al. Randomized phase III study comparing the efficacy and safety of irinotecan plus S-1 with S-1 alone as first-line treatment for advanced gastric cancer (study GC0301/TOP002). Gastric Cancer. 2011;14(1):72-80.

30. Kim YH, Koizumi W, Lee KH, et al. Randomized phase III study of S-1 alone versus $\mathrm{S}-1$ plus docetaxel (DOC) in the treatment for advanced gastric cancer (AGC): the START trial [abstract]. J Clin Oncol. 2011;29 Suppl 4:7. 
31. Asan Medical Center. Trial of 3-weekly Versus 5-weekly Schedule of S-1 Plus Cisplatin in Gastric Cancer (SOS). In: ClinicalTrials.gov [Internet]. Bethesda, MD: National Library of Medicine (US). June 5, 2009 [updated on September 26, 2011]. Available from: http://clinicaltrials. gov/ct2/show/NCT00915382. NLM identifier: NCT00915382.

32. Ajani JA, Faust J, Ikeda K, et al. Phase I pharmacokinetic study of S-1 plus cisplatin in patients with advanced gastric carcinoma. J Clin Oncol. 2005;23(28):6957-6965.

33. Lenz HJ, Lee FC, Haller DG, et al. Expanded safety and efficacy data on $\mathrm{S}-1$ plus cisplatin in patients with untreated, advanced gastric carcinoma in a multicenter phase II study. Cancer. 2007;109(1):33-40.

34. Ajani JA, Lee FC, Singh DA, et al. Multicenter phase II trial of S-1 plus cisplatin in patients with untreated advanced gastric or gastroesophageal junction adenocarcinoma. J Clin Oncol. 2006;24(4):663-667.

35. Ajani JA, Rodriguez W, Bodoky G, et al. Multicenter phase III comparison of cisplatin/S-1 with cisplatin/infusional fluorouracil in advanced gastric or gastroesophageal adenocarcinoma study: the FLAGS trial. J Clin Oncol. 2010;28(9):1547-1553.

36. Sakuramoto S, Sasako M, Yamaguchi T, et al. Adjuvant chemotherapy for gastric cancer with S-1, an oral fluoropyrimidine. $N$ Engl J Med. 2007;357(18):1810-1820.

37. Bonenkamp JJ, Hermans J, Sasako M, et al. Extended lymph-node dissection for gastric cancer. N Engl J Med. 1999;340(12):908-914.

38. Cuschieri A, Weeden S, Fielding J, et al. Patient survival after D1 and D2 resections for gastric cancer: long-term results of the MRC randomized surgical trial. Surgical Co-Operative Group. Br J Cancer. 1999;79(9-10):1522-1530.

39. Sasako M, Sano T, Yamamoto S, et al. D2 lymphadenectomy alone or with para-aortic nodal dissection for gastric cancer. $N$ Engl J Med. 2008;359(5):453-462.
40. Kang YK, Kang WK, Shin DB, et al. Capecitabine/cisplatin versus 5-fluorouracil/cisplatin as first line therapy patients with advanced gastric cancer: a randomised phase III noninferiority trial. Ann Oncol. 2009;20(4):666-673.

41. Cunningham D, Starling N, Rao S, et al. Capecitabine and oxaliplatin for advanced esophagogastric cancer. N Engl J Med. 2008;358(1):36-46.

42. Lee JL, Kang YK, Kang HJ, et al. A randomised multicentre phase II trial of capecitabine vs S-1 as first-line treatment in elderly patients with metastatic or recurrent unresectable gastric cancer. Br J Cancer. 2008;99(4):584-590.

43. Kang Y, Ohtsu A, Van Cutsem E, et al. AVAGAST: a randomized, double-blind, placebo-controlled, phase III study of first-line capecitabine and cisplatin plus bevacizumab or placebo in patients with advanced gastric cancer (AGC) [abstract]. J Clin Oncol. 2010;28 Suppl 18:LBA4007.

44. Bang YJ, Van Cutsem E, Feyereislova A, et al. Trastuzumab in combination with chemotherapy versus chemotherapy alone for treatment of HER2-positive advanced gastric or gastro-oesophageal junction cancer (ToGA): a phase 3, open-label, randomised controlled trial. Lancet. 2010;376(9742):687-697.

45. Okines AF, Ashley SE, Cunningham D, et al. Epirubicin, oxaliplatin, and capecitabine with or without panitumumab for advanced esophagogastric cancer: dose-finding study for the prospective multicenter, randomized, phase II/III REAL-3 trial. J Clin Oncol. 2010;28(25):3945-3950.
OncoTargets and Therapy

\section{Publish your work in this journal}

OncoTargets and Therapy is an international, peer-reviewed, open access journal focusing on the pathological basis of all cancers, potential targets for therapy and treatment protocols employed to improve the management of cancer patients. The journal also focuses on the impact of management programs and new therapeutic agents and protocols on

\section{Dovepress}

patient perspectives such as quality of life, adherence and satisfaction. The manuscript management system is completely online and includes a very quick and fair peer-review system, which is all easy to use. Visit http://www.dovepress.com/testimonials.php to read real quotes from published authors. 